\title{
GEOLOGY
}

\section{RESEARCH ON THE FRACTAL STATISTICAL CHARACTERISTICS AS POSSIBLE PROGNOSTIC PARAMETERS FOR EARTHQUAKES, GENERATED IN THE SEISMIC ZONE OF VRANCEA, IN THE PERIOD BETWEEN 01.08.2016 AND 30.12.2016}

\author{
E. Oynakov, D. Solakov, I. Aleksandrova \\ National Institute of Geophysics, Geodesy, and Geography, Bulgarian Academy of Sciences
}

DOI: https://doi.org/10.31435/rsglobal_wos/31082019/6649

\section{ARTICLE INFO}

Received: 15 June 2019

Accepted: 12 August 2019

Published: 31 August 2019

\section{KEYWORDS}

Fractal analysis,

microseismic noise, prognostic earthquakes. \begin{abstract}
Using fractal analysis is an excellent alternative method for decode the seismic noise structure. Fractal analysis of microseismic noise could also be an appropriate method to detect earthquake indicators. The scientific goal is to detect standard signals, based on different earthquakes' focal mechanisms, separating the "individual" behavior of the elements of the monitoring systems.

The method for describing low-frequency microseismic noise from the network of seismic stations in a seismically active region of the Vrancea used. Seismic records of twenty-three broadband stations were analyzed, situated at distances of 20 to $500 \mathrm{~km}$ from the Vrancea earthquakes whit magnitudes $\mathrm{Mw}=5.7$ and $\mathrm{Mw}=5.6$ on September 23 and December 27, 2016 , respectively. The daily assessment values of three multifractal parameters (characteristics of the multifractal singularity spectra of the waveform) from each station used for the description.

The present paper is a continuation of previous work [Oynakov et al., 2019], where the effects of synchronization in the low-frequency microseismic field were found before the Vrancea earthquake with magnitude $\mathrm{Mp}=5.6$ on October 28, 2019.

The study shows that the noise coherence measure increased for stations, closer to the epicenter. However, the question of the source of this coherence remains open.
\end{abstract}

Citation: E. Oynakov, D. Solakov, I. Aleksandrova. (2019) Research on the Fractal Statistical Characteristics as Possible Prognostic Parameters for Earthquakes, Generated in the Seismic Zone of Vrancea, in the Period Between 01.08.2016 and 30.12.2016. International Academy Journal Web of Scholar. 8(38), Vol.1. doi: 10.31435/rsglobal_wos/31082019/6649

Copyright: (C) 2019 E. Oynakov, D. Solakov, I. Aleksandrova. This is an open-access article distributed under the terms of the Creative Commons Attribution License (CC BY). The use, distribution or reproduction in other forums is permitted, provided the original author(s) or licensor are credited and that the original publication in this journal is cited, in accordance with accepted academic practice. No use, distribution or reproduction is permitted which does not comply with these terms.

1. Relevance and shape of the problem. The number of publications on the seismic prognostic properties of the seismic noise in the minute time range of oscillation periods has increased in recent years. For example, the articles of (Sobolev et al., 2008; Lyubushin, Sobolev, 2006) examine the periodic structure of the seismic noise, recorded by broadband stations in Kamchatka, Japan, and Sakhalin. It was found that impulse fluctuations with a duration of several minutes, one after another, within several tens of minutes, occur in the records before strong earthquakes with $\mathrm{M}_{\mathrm{w}}=7.5-8.3$.

Results aimed at the operational determination of the signs for preparation and prediction of strong earthquakes, based on data from low-frequency noise variations, are presented in the articles of Lyubushin, 2006, 2007. The methodology presented here informed in this research. 
In the paper Oynakov, E., I. Aleksandrova 2019 is shown that the transition from an analysis of baseline low-frequency microseismic data to the study of the variations of the multifractal statistical parameters allows detecting hidden effects of synchronization before the earthquake of 28.10.2018 in the Vrancea region. The study of the Hurst $(H)$ parameter (Oynakov, E. et al. 2019) shows that for the stations, located in the epicenter zone, it increases about 3-4 days before the earthquake and for the stations located at a longer distance it increases about 2-4 days before the earthquake. High $\mathrm{H}$ values detected from 2 to 3 days before other seismic events with smaller magnitude. The analysis of the overtime development of the width of the spectrum of singularity indicates that all earthquakes in the analyzed time interval are preceded by 1.5 to 4 days by the parameter minimums. The spectral timing diagrams of the coherent behavior of the seismic signal for all stations evaluated in a time window of 7200 minutes (5 days) with an offset of 60 minutes (1 hour) for the interval $06.10-28.10 .2018$ indicate the synchronization of the stations in the epicenter area from 9 to 3 days before the earthquake. For remote stations, the synchronization of the seismic signal starts 9 days before the earthquake.

This paper explores two other earthquakes (23.09.2016; $\mathrm{T}_{0}=11: 11: 20 \mathrm{GMT}$; with coordinates $45.71 \mathrm{~N}, 26.62 \mathrm{E} ; \mathrm{M}_{\mathrm{w}}=5.7$ and 27.12.2016; $\mathrm{T}_{0}=11: 20: 56.3 \mathrm{GMT}$; with coordinates $45.72 \mathrm{~N}, 26.61 \mathrm{E}$; $\mathrm{M}_{\mathrm{w}}=5.6$ ), occurred in the Vrancea seismic zone in 2016 .

\section{Methodology and used data.}

This paper explores the time interval of 01.08.2016. - 30.12.2016, involving two seismic events with $\mathrm{M}_{\mathrm{w}}>5.5$ :

- the earthquake of 23.09.2016; 11:11:20 GMT; with coordinates $45.71^{\circ} \mathrm{N} / 26.62^{\circ} \mathrm{E} ; \mathrm{M}_{\mathrm{w}}=5.7$; $\mathrm{h}=92 \mathrm{~km}$;

- the Vrancea earthquake on 27.12.2016; 11:20:56.3 GMT; with coordinates $45.72^{\circ} \mathrm{N} /$ $26.61^{\circ} \mathrm{E} ; \mathrm{M}_{\mathrm{w}}=5.6 ; \mathrm{h}=91 \mathrm{~km}$.

Table 1. Seismic stations used in the study. The last 2 columns represent the time intervals and the number of 24-hour seismic records, used in the research.

\begin{tabular}{|c|c|c|c|c|c|c|}
\hline $\begin{array}{l}\text { Seismic } \\
\text { stations }\end{array}$ & Digitizer & $\begin{array}{c}\text { Latitude } \\
\left({ }^{\circ} \mathrm{N}\right)\end{array}$ & $\begin{array}{l}\text { Longitu } \\
\text { de }\left({ }^{\circ} \mathrm{E}\right)\end{array}$ & Sensors & $\begin{array}{c}\text { Period } \\
01.08 .16 \\
- \\
23.09 .16 \\
\text { Number } \\
\text { of } 24 \\
\text { hour } \\
\text { records }\end{array}$ & $\begin{array}{c}\text { Period } \\
24.09 .16- \\
30.12 .16 \\
\text { Number of } \\
24 \text { hour } \\
\text { records }\end{array}$ \\
\hline AVR & RefTek DAS 130-3/6 & 43,1178 & 27,6685 & GEOPHON & 54 & 98 \\
\hline $\mathrm{BOZ}$ & RefTek DAS 130-3/6 & 43,1044 & 27,4786 & GEOPHON & 54 & 98 \\
\hline DOB & RefTek DAS 130-3/6 & 43,1790 & 27,4628 & GEOPHON & 54 & 98 \\
\hline PRD & RefTek DAS 130-3/6 & 43,1602 & 27,4099 & & 54 & 98 \\
\hline NEF & RefTek DAS 130-3/6 & 43,2644 & 27,2753 & S13 & 54 & 98 \\
\hline ROIA & RefTek DAS 130-3/6 & 43,0934 & 27,3778 & GEOPHON & 54 & 98 \\
\hline PSN & RefTek DAS 130-3/6 & 43,6376 & 28,1359 & KS2000/60s & 54 & 98 \\
\hline PVL & RefTek DAS 130-3/6 & 43,1227 & 25,1732 & CMG 3ESPC/120 & 54 & 98 \\
\hline MPE & RefTek DAS 130-3/6 & 43,3560 & 23,7401 & S13 & 54 & 98 \\
\hline SZH & RefTek DAS 130-3/6 & 43,2653 & 25,9762 & CMG3ESPC/120 & 54 & 98 \\
\hline ORH & RefTek DAS 130-3/6 & 43,7263 & 23,9664 & S13 & 54 & 98 \\
\hline VLD & RefTek DAS 130-3/6 & 43,6899 & 23,4356 & S13 & 54 & 98 \\
\hline VRI & Altus-K2 & 45,8665 & 26,2764 & CMG3ESP & 54 & 98 \\
\hline DRGR & Altus-K2 & 46,7917 & 22,7111 & KS54000 & 54 & 98 \\
\hline DJES & & 44,6659 & 22,5199 & & 54 & 98 \\
\hline PLOR & Q330 & 26,6498 & 45,8512 & STS2 & 54 & 98 \\
\hline PLOR1 & Q330 & 45,8520 & 26,6466 & CMG-40T & 54 & 98 \\
\hline PLOR2 & Q330 & 45,8502 & 26,6437 & CMG-40T & 54 & 98 \\
\hline PLOR3 & Q330 & 45,8539 & 26,6454 & CMG-40T & 54 & 98 \\
\hline PLOR4 & Q330 & 45,8512 & 26,6498 & CMG-40T & 54 & 98 \\
\hline PLOR5 & Q330 & 45,8455 & 26,6635 & CMG-40T & 54 & 98 \\
\hline PLOR6 & Q330 & 45,8419 & 26,6415 & CMG-40T & 54 & 98 \\
\hline PLOR7 & Q330 & 45,8603 & 26,6405 & CMG-40T & 54 & 98 \\
\hline & & & & & 1242 & 2254 \\
\hline
\end{tabular}


For the study, vertical component records (BHZ) of 23 seismic stations (Table 1), with records of 100 reports per second (i.e., 8640000 reports for 24 hours) used. We to obtain 1/2-minute lowfrequency noise time series, the average values of the original recordings at successive time intervals of 3000 reports calculated for each station $-1 / 2$ minute time series obtained for all 23 stations.

Eight of the seismic stations - PLOR, PLOR1, PLOR2, PLOR3, PLOR4, PLOR5, PLOR6 and PLOR7 (Local Ploeschina network) located in the epicenter region (average $20 \mathrm{~km}$ from the epicenters of the two earthquakes) of the Vrancea seismic zone, VRI and DRGR stations are located at distances of 30 and $450 \mathrm{~km}$ respectively from the earthquake epicenters. All ten listed seismic stations are part of the seismic network of Romania. The seismic stations PRD, AVR, BOZ, DOB, NEF, and ROIA, are part of the Provadia Local Seismic Network (LSN-Provadia). They are at an average distance of $400 \mathrm{~km}$ from the epicenters of the two earthquakes, the PSN, PVL, MPE, SZH, ORH and VLD seismic stations are part of the seismic network of Bulgaria and located at approximately $370 \mathrm{~km}, 430$ $\mathrm{km}, 470 \mathrm{~km}, 380 \mathrm{~km}, 420 \mathrm{~km}$ and $460 \mathrm{~km}$ from the epicenters, respectively. The DJES seismic station is part of the seismic network of Serbia and is at approximately $470 \mathrm{~km}$ from the epicenters.

By the used methodology are estimated three informative fractal statistics at consecutive time intervals of 2880 report (1 day) for 1/2-minute time series for each station. The estimation of the noise statistics is made after removing of the low-frequency trends with an $8^{\text {th }}$ order polynomial. Trend filtering is required to eliminate the effects of tidal and temperature deformations of the Earth's crust in the seismic noise variations and is a necessary procedure for noise's statistical characteristics studying. Using an orthogonal polynomial enables the stability of the trend evaluations at the reading points. In this case, the order of the polynomial $\left(8^{\text {th }}\right)$ was chosen as the smallest one after numerical experiments, thus allowing the elimination of the day-to-day variations for the intervals of one-day duration (Lyubushin, A.A. 2007). The question of the regularity of the transition in such a low-frequency domain of seismic signal recordings naturally arises.

It should be noted that the development of broadband seismological equipment did not consider its use for continuous seismic recording over a more extensive frequency range beyond the earthquake signal frequencies, and is not assumed that seismic sensors could also be used as the usual inclinometer, i.e., to register the change of signal in the tidal band frequencies. Following numerical experiments (Lyubushin AA, 2008), we believe that in solving geophysical monitoring tasks and investigating earthquake preparation processes, there is a theoretical possibility for broader use of broadband seismological equipment that exceeds the formal operating frequency limitations, which is traditionally used to study individual earthquakes. Fig. 1 illustrates this assumption. Continuous seismic noise recordings of eight stations are considered, and an 1-hour discretization step is performed. From the initial records at a sampling rate of $100 \mathrm{~Hz}$, the average value was calculated at consecutive time intervals with length of 360,000 samples (1-hour length). In this way, the traditional for gravimetry frequency range is provided. If adhering to the traditional view of such a procedure, the transition to an hourly discretization step seems unacceptable but the graphs of the time series on Fig.1a are similar to the inclinometers records.

Moreover, if we look at the power spectra of the temporal variations of the seismic noise recorded with the used instrumentation (Table 1), we see the manifestation of tidal 12 and 24-hour spectral extremum, even separation of different tidal harmonics at sufficient length of time series (Fig. $2 \mathrm{~b}$ ). This example shows that the signal recorded with modern broadband seismometers contains lowfrequency components, significantly exceeding the formal limits specified in their technical passports by the manufacturer. It is these undocumented and poorly understood capabilities of broadband seismometers that could be used in this study.

It should also be pointed out that all of the used noise statistics are dimensionless and do not depend on the scale of the input data. This significantly reduces the dependence on the different seismometers used. 

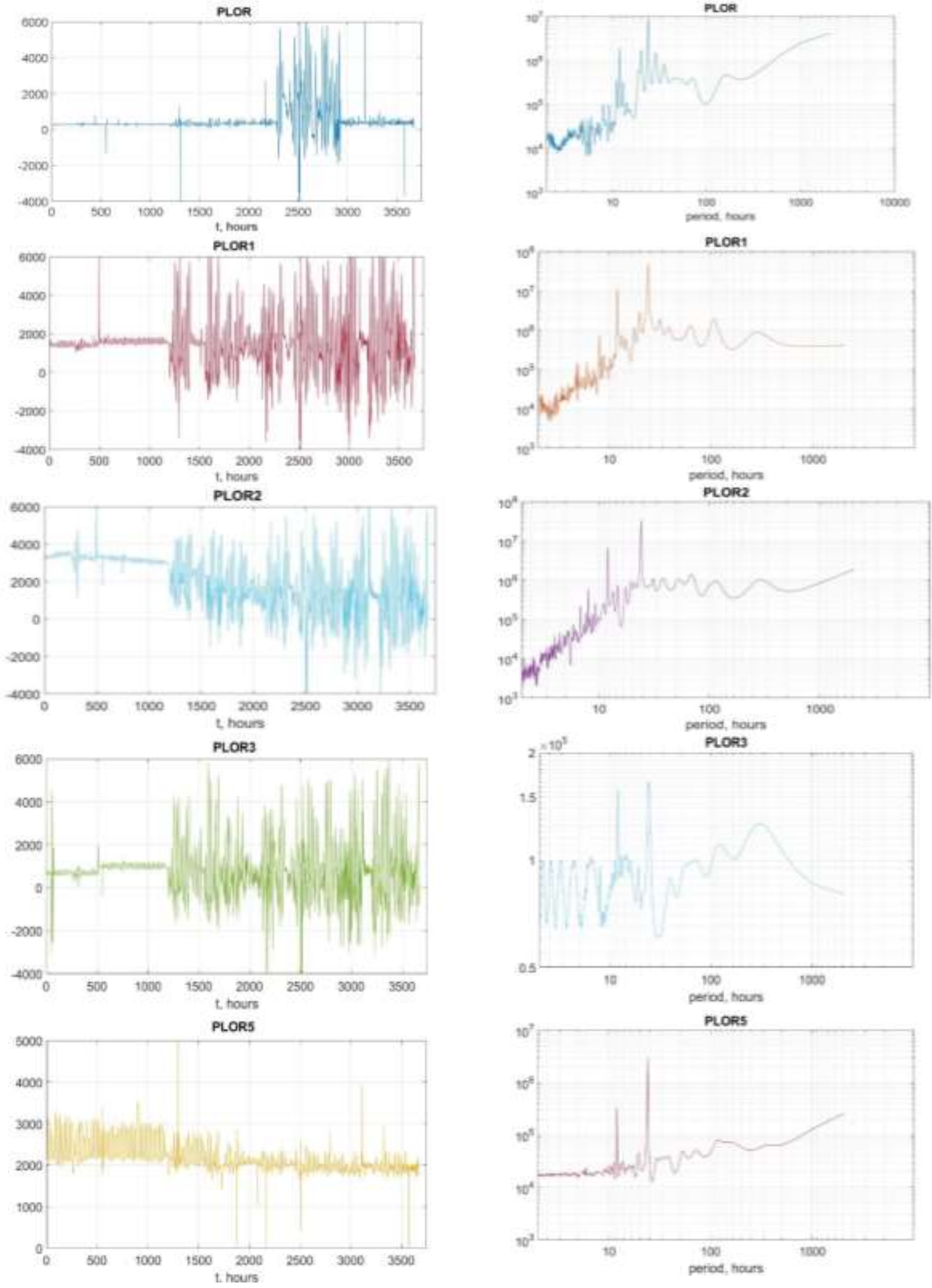

Fig. 1. a) Fragments of continuous seismic records from five stations in the seismogenic zone of Vrancea, with a length of 152 days after the transition to a step in 1 hour; $b$ ) the corresponding power spectra; On the left are presented graphs, where the origin units of seismic records indicated on the ordinate axes and the right - the spectral density of the dispersion at a given frequency. 


\section{Obtained results}

\subsection{Hurst exponent}

The interest towards the positive value of the Hurst exponent estimate $(H>0)$ is related to the fact that for self-similar processes it is in the interval $0<H<1$ (Kantelhardt, Jan W., et al., 2002). Therefore, $H(\tau)>0$ represents a sign of self-similar fractal behavior of low-frequency seismic noise indirectly. For the calculation of the Hurst exponent is used the DFA (Detrended Fluctuation Analysis) method, described in Oynakov, E. et al. 2019.

To verify that before earthquakes of magnitude larger than $\mathrm{Mw}=5.5$ in the seismogenic zone Vrancea, the Hurst $(H)$ exponent increases both earthquakes in 2016 were studied. Fig. 2 represents the coordinates and magnitudes of all earthquakes, occurred in the analyzed area, during the time interval 01.08-30.12.2016. Fig. 3 shows a graph of the synchronous maximum of $H$ in the period 01.08-30.12.2016, for the stations of the Local Ploeschina network. We can summarize that 12 days before the earthquake on September 23, 2016, and 8 days before the earthquake of December 27, 2016, the values of $H$ have increased (Fig. 3).

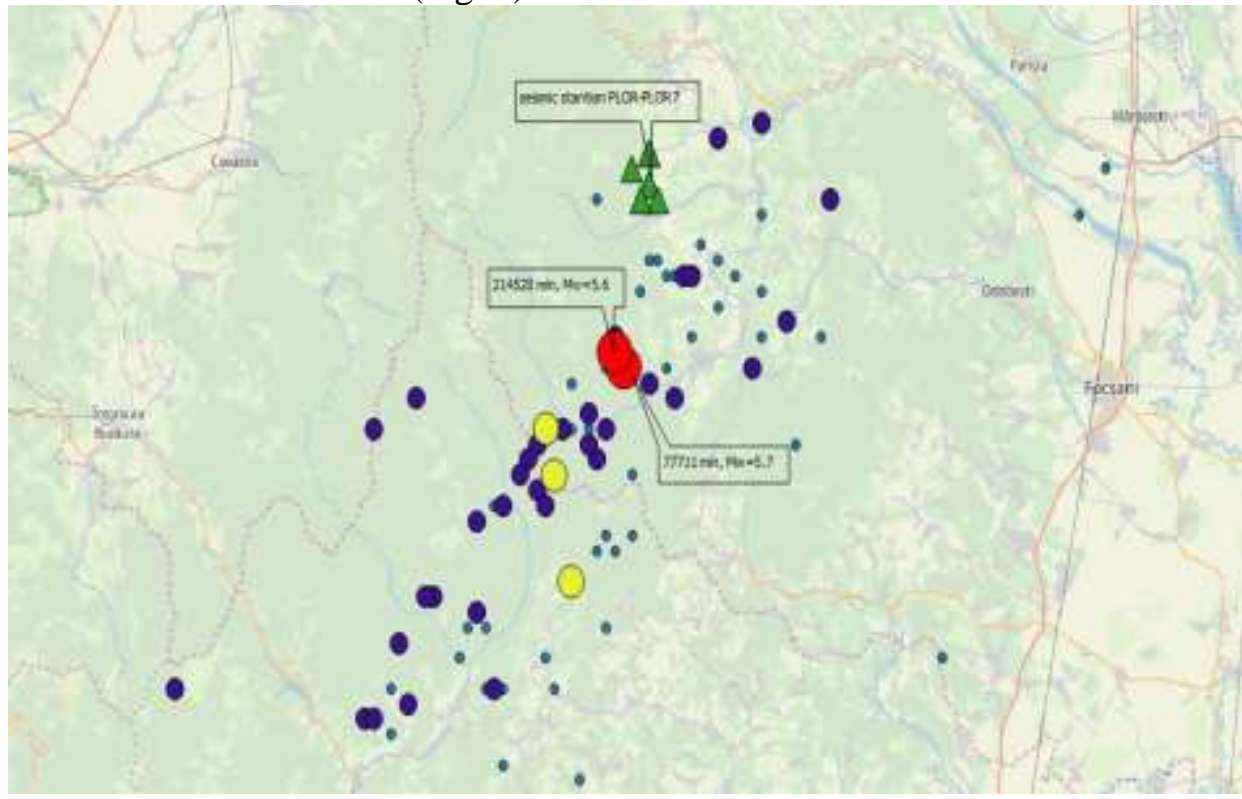

Fig.2. Map of the coordinates and magnitudes of the earthquakes that occurred in the analyzed area in the period 01.08-30.12.2016; $-5 \leq M w \leq 6$; $-4 \leq M w \leq 5$; $-3 \leq M w \leq 4 ; \bullet-2 \leq M w \leq 3$. The seismic stations in the Ploieština local area network indicated with green triangles.

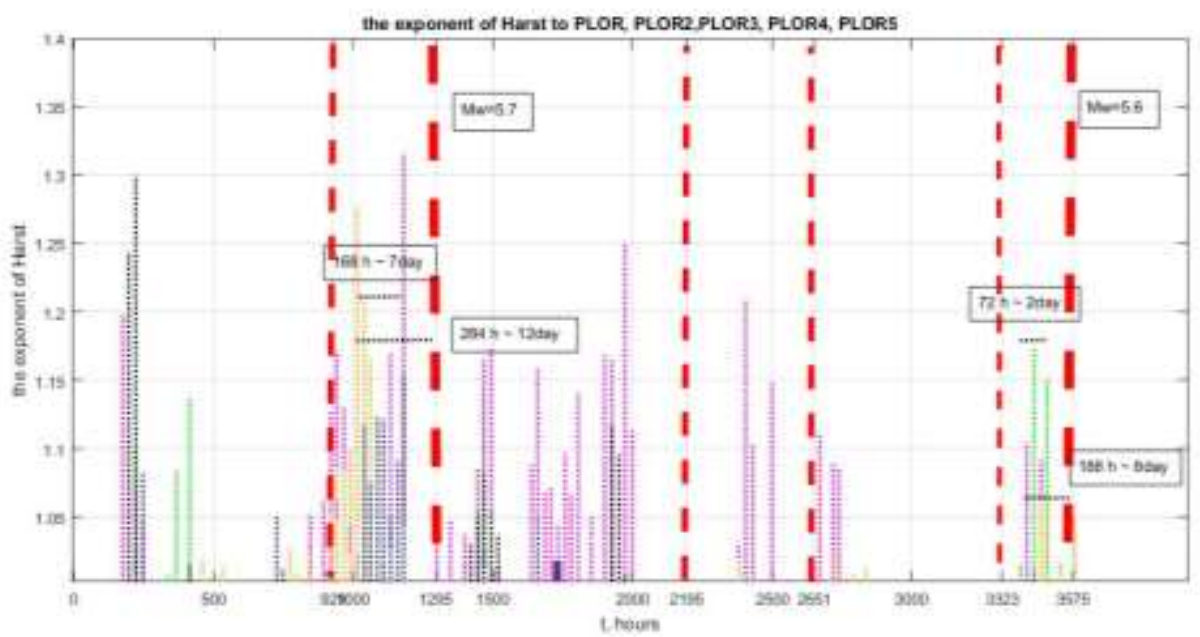

Fig. 3 Graph of the change of H> O for PLOR, PLOR2, PLOR3, PLOR4, PLOR5 stations; the red dashed lines show the moments of the earthquakes that occurred in the analysed area in the period 01.08-30.12.2016 -08.09.2016 ( $M w=4.1) ; 09.23 .2016(M=5.7) ; 10.31 .2016(M w=4) ; 11.19 .2016(M w=4.1) ; 11.30 .2016$ $(M w=3.5) ; 12.17 .2016(M w=3.9)$ and 12.27.2016 (Vrancea, $\left.T_{0}=00: 38: 15 ; 45.7 N, 26.4 E ; M w=5.6\right)$. The text boxes show the time from $\mathrm{H}$ maxima to the earthquake moments in minutes and days. 


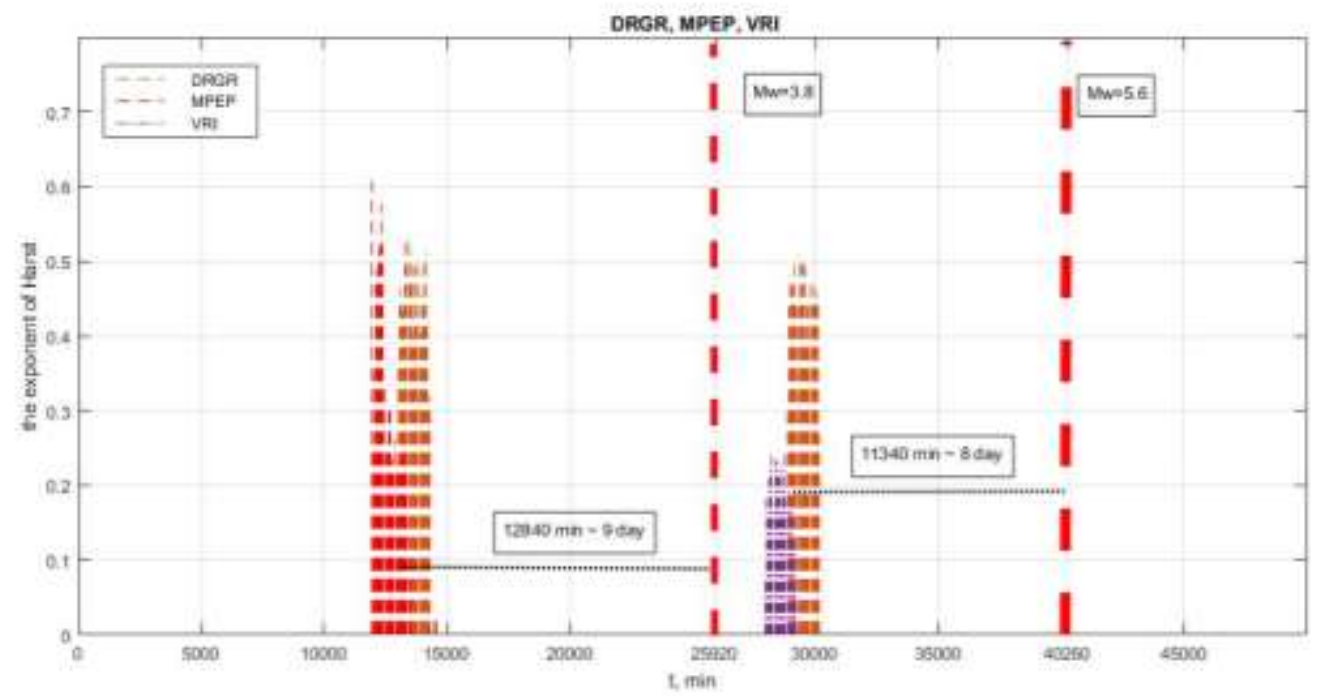

Fig. 4 Graph of the change of $H>0$ for DRGR, MPEP, VRI stations in the period 24.09-30.12.2016. The red dashed lines show the moment of the earthquakes that occurred in the analysed area $-17.12 .16 ; T_{0}=$ 11: 16: 05; 45.50N, 26.47E (Mw = 3.9);) and 27.12.2016 (Vrancea, $T_{0}=12: 38: 15 ; 45.7 \mathrm{~N}, 26.4 \mathrm{~N} ; \mathrm{Mw}=$

5.5). The text boxes show the time from H maxima to the earthquake moments in minutes and days.

Fig. 4 presents in details the graphs of the Hurst exponent evaluations for DRG, MPEP, VRI stations in the period 23.09-30.12.2016 before the earthquake of December 27, 2016 (Vrancea, Mw = 5.6). The zero of the time axis corresponds to $\mathrm{T}_{0}=00: 00: 00$ (GMT) on 23.09.2016. It can be noted that the maximum of the Hurst exponent is present not only before the earthquake of 27.12.2016 but also $\sim 9$ days before the earthquake of 17.12.2016, $\mathrm{T}_{0}=11: 16: 05$ (GMT) with coordinates $45.5 \mathrm{~N}$, 26.47E and $\mathrm{Mw}=3.8$.

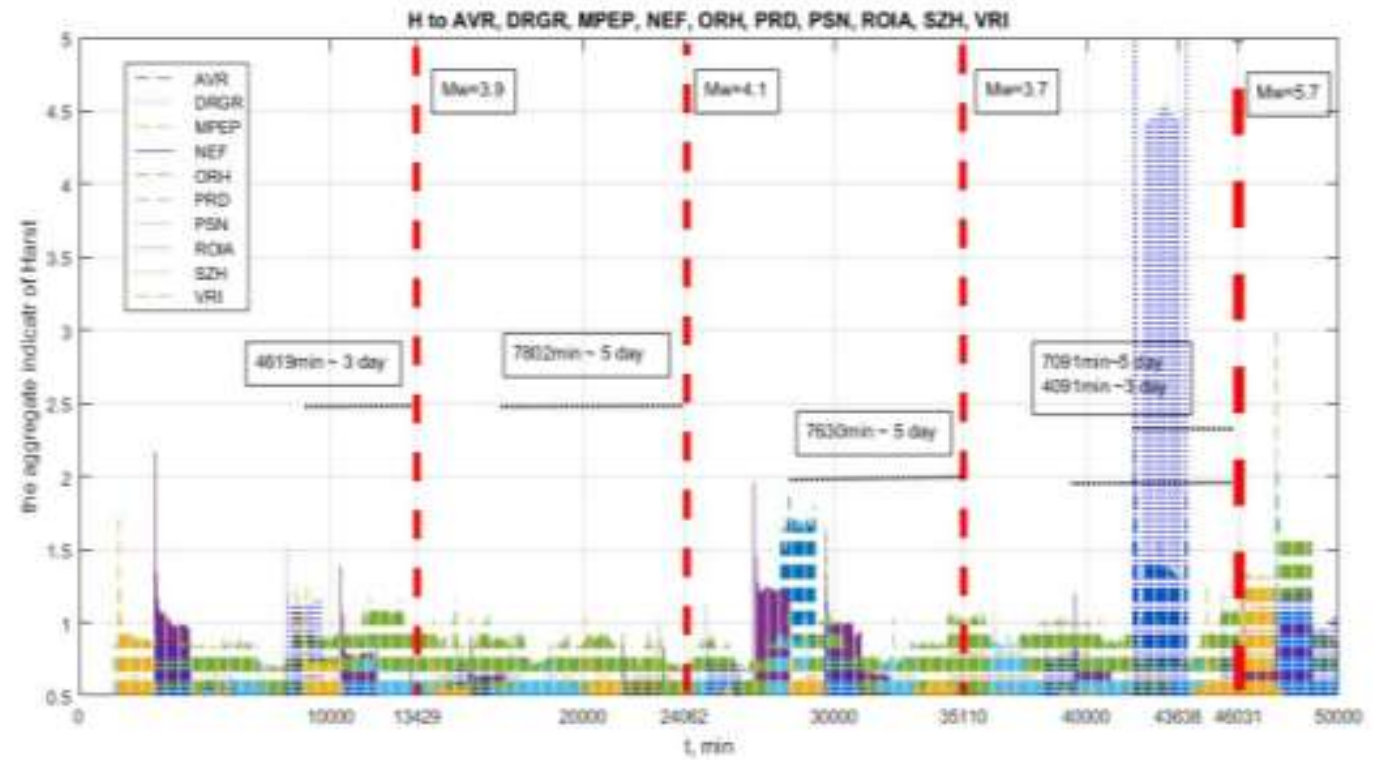

Fig. 5 Graph of the change of $H>0$ for AVR, DRGR, MPEP, NEF, ORH, PRD, PSN, ROIA, SZH, VRI stations in the period 23.08-23.09.2016. The red dashed lines indicate the time of the earthquakes that occurred in the analysed area -01.09.2016; $T_{0}=07: 49: 21(G M T) ; 45.67 N, 26.33 E(M w=3.9)$; 08.09.2016; $T_{0}=17: 03: 02 ; 45.67 \mathrm{~N}, 26.53 E(M w=4.1) ; 16.09 .2016 ; T_{0}=09: 10: 57 ; 45.65 \mathrm{~N}, 26.59 E$ $(M w=3.7)$ and 23.09.2016 (Vrancea, $\left.T_{0}=23: 11: 20 ; 45.71 N, 26.62 E ; M=5.7\right)$. The text boxes show the time from $H$ maxima to the earthquake moments in minutes and days. 
Fig, 5 shows in details the graphs of the Hurst indicator evaluations for stations AVR, DRGR, MPEP, NEF, ORH, PRD, PSN, ROIA, SZH, VRI before the earthquake of 23.09.2016. (Vrancea, Mw $=5.7$ ). The zero of the time axis corresponds to $23.08 .2016,00^{\mathrm{h}} 00^{\mathrm{m}}($ GMT). Three more seismic events occur in the analysed period $\left(01.09 .2016 ; \mathrm{T}_{0}=07: 49: 21 ; 45.67 \mathrm{~N}, 26.33 \mathrm{E}(\mathrm{Mw}=3.9)\right.$; 08.09.16; $\left.\mathrm{T}_{0}=17: 03: 02 ; 45.67 \mathrm{~N}, 26.53 \mathrm{E}(\mathrm{Mw}=4.1)\right) ; 16.09 .2016 ; \mathrm{T}_{0}=09: 10: 57 ; 45.65 \mathrm{~N}, 26.59 \mathrm{E}$ $(\mathrm{Mw}=3.7))$ and it can be noted that 3 to 5 days before each event there is a synchronous maximum of $H$ for all stations. The figure also shows that the Hurst indicator for all stations is $H>0$.

\subsection{Singularity spectrum width}

The parameter $\Delta \alpha=\alpha_{\max }-\alpha_{\min }$ (Feder E., 1991), also called the width of the singularity spectrum, represents one of the important multifractal characteristics and assessment for the variety of random signal behavior. The statistically significant decrease in the average value of $\Delta \alpha$ reflects the decrease in the degrees of system's freedom, generating a signal and thus enables the determination of the time of preparation of an earthquake.

Fig. 6 presents the overall assessment of the parameter $\Delta \alpha$ for all stations on the PLOR LAN (i.e., the average value of $\Delta \alpha$ ). For each station, $\Delta \alpha$ is calculated in consecutive non-intersecting windows with a length of 24 hours and a shift of 1 hour over the entire time interval (01.08-30.12.2016, 22 days), after which the average value for the local area network are obtained. One feature of the smoothed $\Delta \alpha$ schedule are the minimums in the 59400 and 199700 minutes, 13 and 10 days before the earthquakes on 23.09.2016 and 27.12.2016, respectively, which, as we have indicated above, measures the number of hidden degrees of freedom of the stochastic systems. The other earthquakes in the analyzed time interval are preceded by a minimum of the width index of the singularity spectrum from 6 to 7 days. We may also note a large minimum of $\Delta \alpha$ at 95040 minutes, which precedes the earthquakes at 109796, 119710, and 131759 minutes, and can be assumed to be related to them.

Fig. 7 shows the evolution of the width parameter of the spectrum of singularity $\Delta \alpha$ for the interval 23.08-23.09.2016 for different station combinations. The $\Delta \alpha$ parameter for each station calculated for the same length of the time window ( 24 hours $=2880$ reports) and the same displacement $(1$ hour $=120$ reports). Minima of $\Delta \alpha$ can be determined both 6-7 days before the earthquake with $\mathrm{M}_{\mathrm{w}}=5.7$ (23.09.2016) and 3-5 days before the earthquakes falling within the studied time interval. It should be added that a study on the evolution of the width of the spectrum of singularity before the earthquake of December 27, 2016, was also conducted. $\left(M_{w}=5.6\right)$ in the period 23.08-23.09.16 and the results are identical, i.e., 6-10 days before the earthquake, there is a minimum of $\Delta \alpha$, and 3-4 days before the smaller earthquakes, falling within the analyzed interval.

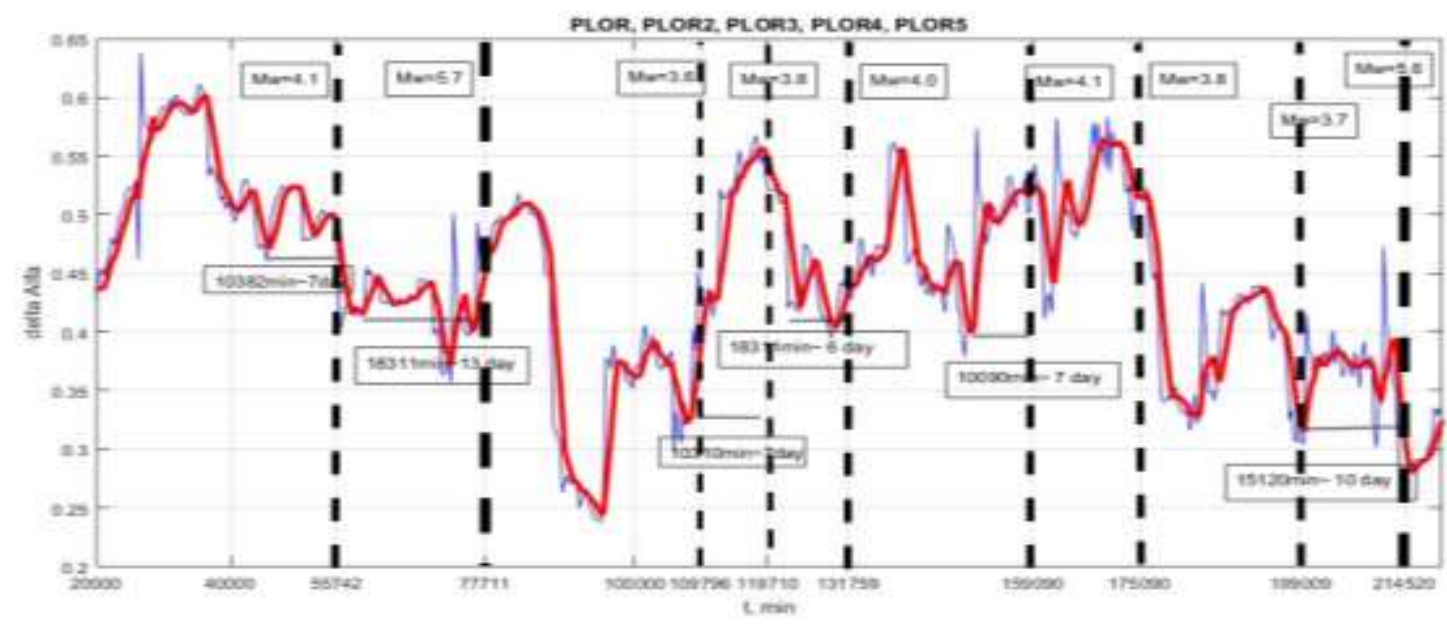

Fig. 6 Graph of the average values of the parameter $\Delta \alpha$, for stations from the local area network Ploeschina. The dashed line indicates all earthquakes, occurrences in the analyzed area for the period. The beginning of the abscissa is 06.10.2018-00:00 hours (GMT). 

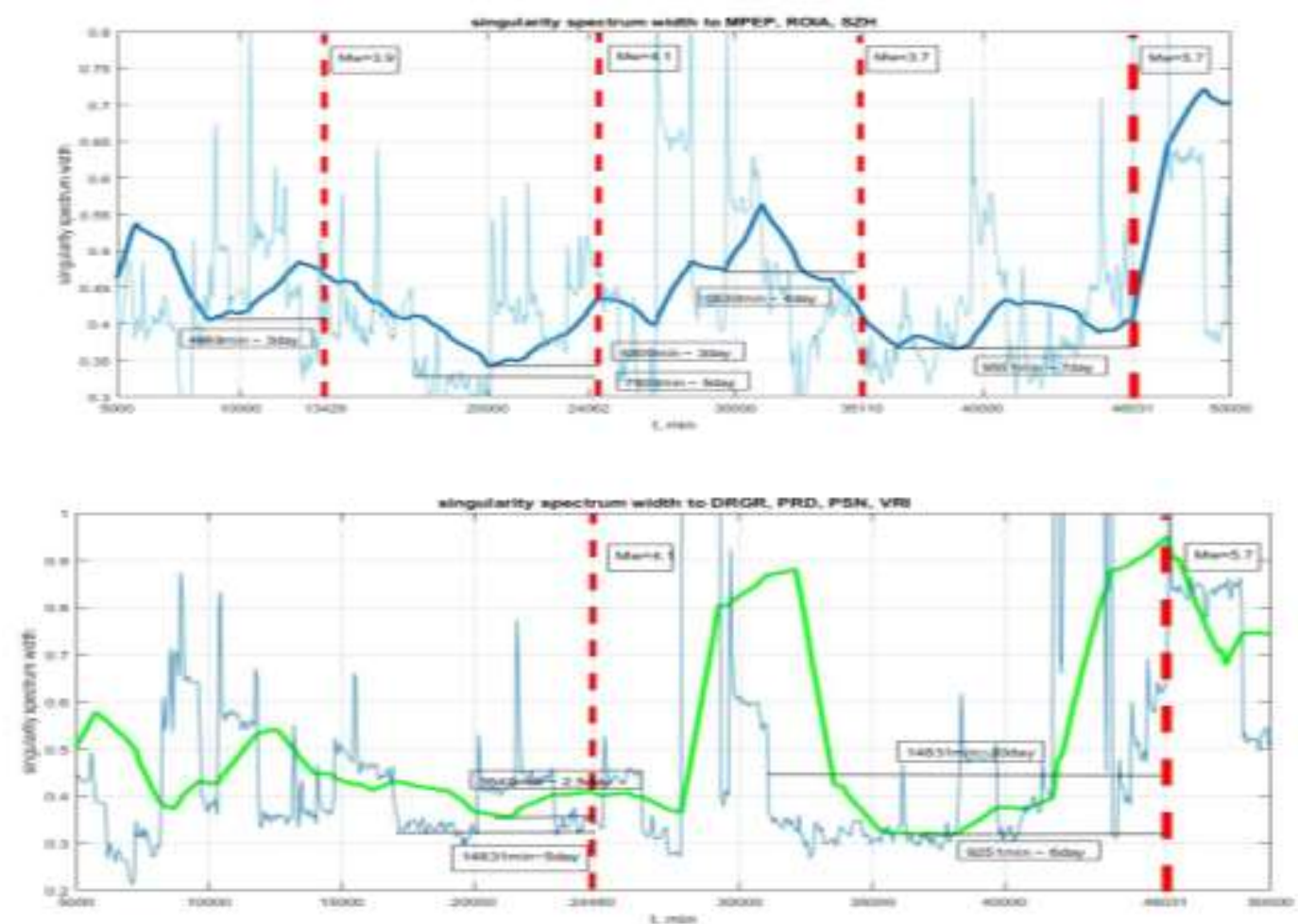

Fig. 7 Graph of the average values of the parameter $\triangle \alpha$ a) for stations - MPEP, ROIA, SZH in the interval 01.08 to 24.09.2016. b) for stations - DRGR, PRD, PSN, VRI in the interval 01.08 to 24.09.2016. The red dashed lines mark the moments of the earthquakes.

\subsection{Spectral Coherence Assessment}

For assessing the synchronization effects of the results measuring of the low-frequency microseismic background for several seismic stations is used the spectral measure of coherence proposed by Lyubushin (1998). It is constructed as a module of the product of the component canonical coherence.

$$
\lambda(\tau, \omega)=\prod_{j=1}^{m}\left|v_{j}(\tau, \omega)\right|,
$$

where $m \geq 2$ is the total number of jointly analyzed time series (the dimension of the multidimensional time series), $\omega$ is the frequency, $\tau$ is the time coordinate of the right edge of the scandent time window, $v_{j}(\tau, \omega)$ is the canonical coherence of the jth scalar time row that describes the relationship between that row and the other ones. The inequality $0 \leq\left|v_{j}(\tau, \omega)\right| \leq 1$ is satisfied. The closer the value of $\left|v_{j}(\tau, \omega)\right|$ is to one, the higher linearly are connected the variations of the j-th order of frequency $\omega$ in the time window with coordinate $\tau$ to the similar variations in other lines studied. Accordingly, measure $0 \leq \lambda(\tau, \omega) \leq 1$ describes the effect of the overall coherent (synchronous, collective) behavior of all signals.

Fig. 8 shows the behavior of the spectral measure of coherent behavior $\lambda(\tau, \omega)$ of the seismic signal for stations PLOR1-PLOR7, in a time window 20160 half minute reports (7 days) with 720 reports (6 hours) shift for the time interval 01.08.2016 - 30.12.2016 (the abscissa timestamps indicate the right end of the time window). From the result we can conclude that the signal synchronization of all stations has a maximum of all frequencies in 30000 minutes, which is $\sim 40$ days before the earthquake which is in 77711 minutes $(23.09 .16, \mathrm{Mw}=5.7)$ and maximum in 14000 minutes $-\sim 50$ days before the earthquake in 214520 minutes (December 27, 2016, Mw = 5.6). 


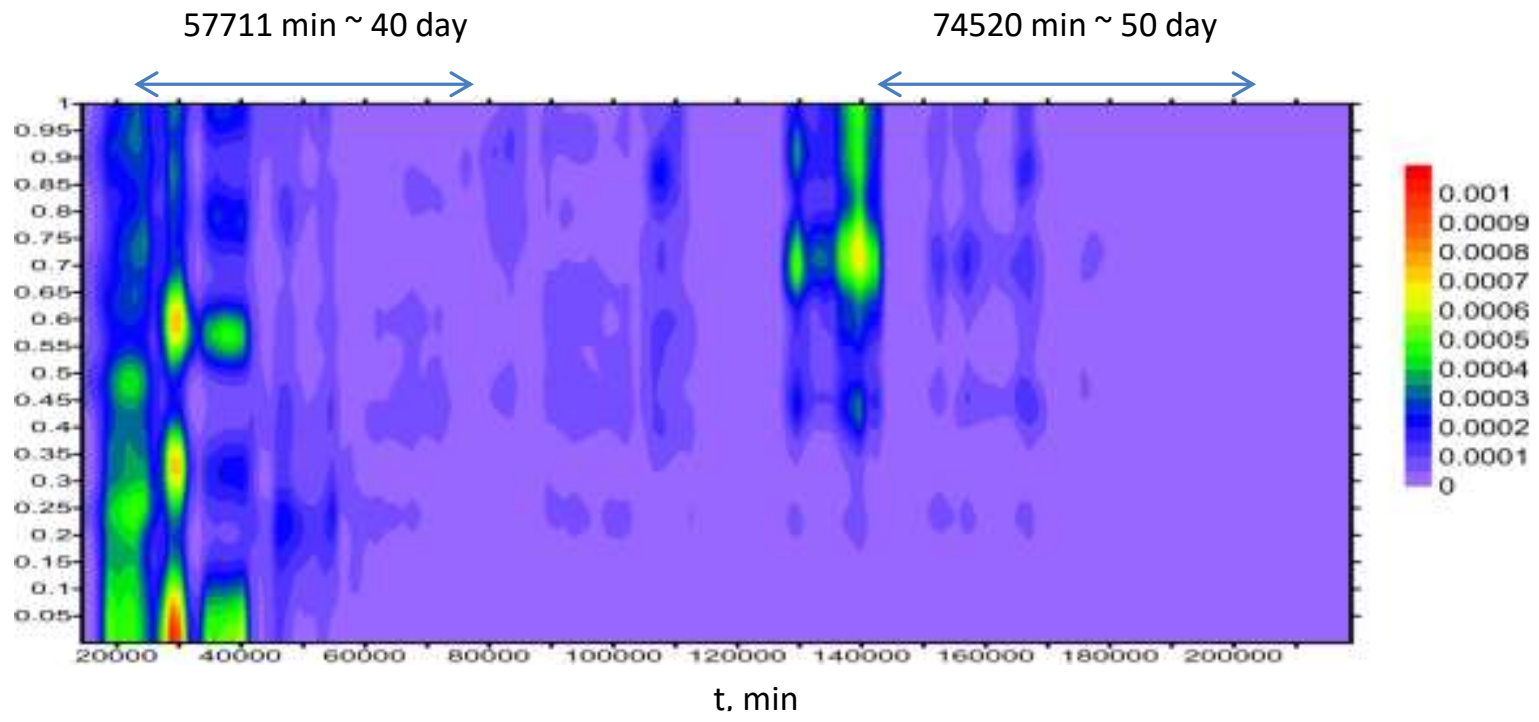

Fig. 8 Frequency-time diagram of the behavior of $\lambda(\tau, \omega)$ for PLOR1-PLOR7 stations. The beginning of the time axis corresponds to 00:00 (GMT) on 01.08.2016 (analyzed time interval from 01.08 to 30.12.2016)

Fig. 9 shows the behavior of the spectral measure of coherent behavior $\lambda(\tau, \omega)$ of the seismic signal for; MPE; NEF; ORH; PSN; PRD; ROIA; SZH; VLD; VRI stations, in time window 20160 half minute reports ( 7 days) with 720 reports (6 hours) shift for the time interval $23.09-30.12 .2016$ (abscissa timestamps indicate the right end of the time window). The signal synchronizations of all stations start from 20000 minutes and reach a maximum of 24000 minutes, which is $\sim 15$ days before the earthquake on December 27, $2016(\mathrm{Mw}=5.6)$.

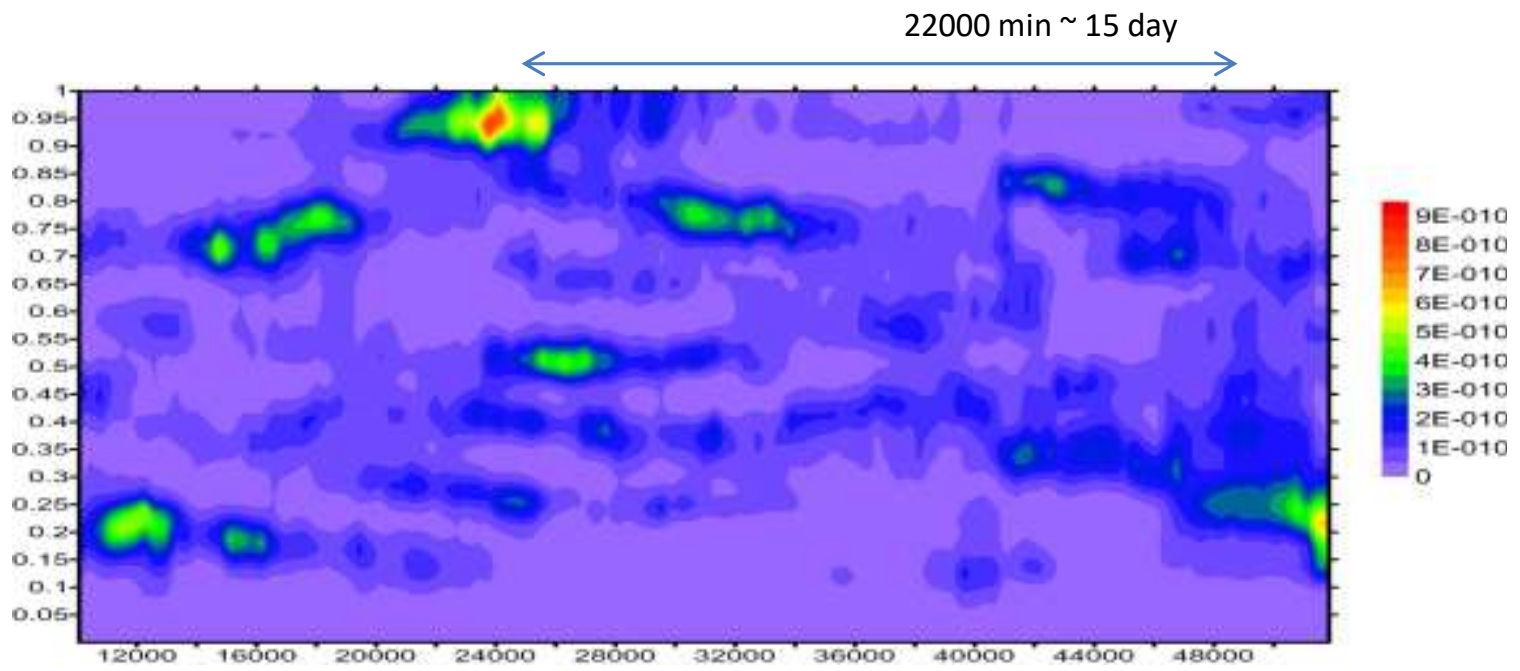

Fig. 9. Frequency-time diagram of the behavior of $\lambda(\tau, \omega)$ for MPE; NEF; ORH; PSN; PRD; ROIA; SZH; VLD; VRI stations, for the time interval 23.09.-30.12.2019. The moment of the earthquake of 27.12.2016 shown with an arrow.

Fig. 10 shows the behavior of the spectral measure of coherent behavior $\lambda(\tau, \omega)$ of the seismic signal for MPE; NEF; ORH; PSN; PRD; ROIA; SZH; VLD; VRI stations, in time window 20160 half minute reports ( 7 days) with 720 reports (6 hours) shift for the interval time 23.08 - 23.09.2016 (abscissa timestamps indicate the right end of the time window). The signal synchronizations of all stations start from 30,000 minutes and reach a maximum of 36,000 minutes, which is $\sim 6$ days before the earthquake on September 23, $2016(\mathrm{Mw}=5.7)$. 


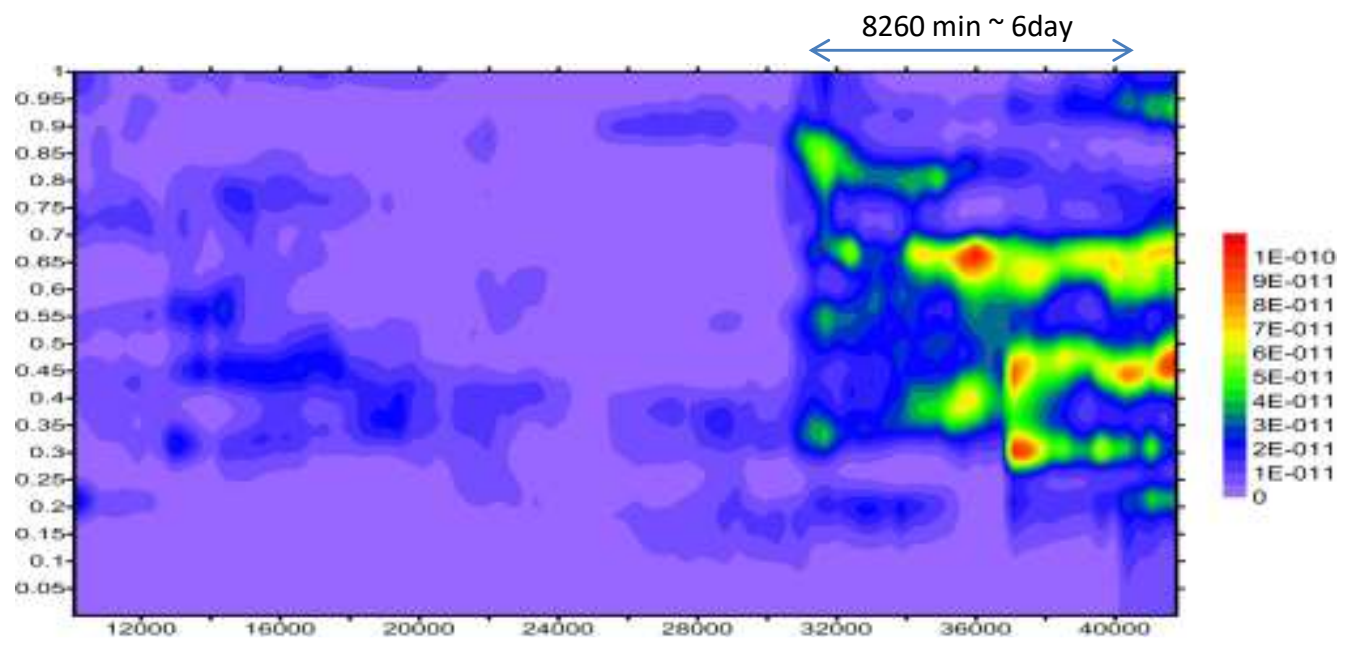

Fig.10. Frequency-time diagram of the behavior of $\lambda(\tau, \omega)$ for MPE; NEF; ORH; PSN; PRD; ROIA; SZH; VLD; VRI stations, for the time interval 23.08.-23.09.2019. The moment of the 23.09.2016 earthquake is shown above with an arrow.

5. Conclusions. The study of the Hurst exponent shows that it increases about 7-8 days before earthquakes with $\mathrm{M}_{\mathrm{w}}>5.5$. High $H$ values were indicated 3 to 5 days before other smaller magnitude seismic events $(3.5 \leq \mathrm{Mw} \leq 5)$.

The analysis of the development of the width of the spectrum of singularity $\Delta \alpha$ shows that earthquakes with $\mathrm{Mw}>5.5$, in the analyzed time interval, are preceded by minimums from 10 to 13 days and minimums of 2 to 7 days before earthquakes with smaller magnitude $(3.5 \leq \mathrm{Mw} \leq 5)$.

The spectral time diagram of the spectral measure of coherent behavior of the seismic signal for epicentral stations, estimated in a time window of 10080 minutes (7 days), with a 360 minutes (6 hours) shift, for the time interval $01.08-30.12 .2016$, shows synchronization of the stations from 40 to 50 days prior to the earthquakes in Vrancea with $\mathrm{Mw}>5.5$. For stations at a greater distance - from 6 to 15 days before the earthquakes (time window 2880 reports, 120 reports shift).

We can conclude that the analysis of the fractal and multifractal parameters of the microseismic field in the minute time range of discretization can provide valuable information about the process of earthquake preparation and the effects, leading to the accumulation of voltage in the lithosphere.

Acknowledgement. This study has been carried out within the framework of the National Scientific Program "Young Scientists and Postdoctoral Fellows", approved by Council of Ministers Decision No 11 / 17.08.2018 and supported by the Ministry of Education and Science (MES) of Bulgaria and of the National Science Program "Environmental Protection and Reduction of Risks of Adverse Events and Natural Disasters", approved by the Resolution of the Council of Ministers № 577/17.08.2018 and supported by the Ministry of Education and Science (MES) of Bulgaria (Agreement № ДО-230/06-12-2018).

\section{REFERENCES}

1. Feder E. Fractals. - M.: Mir, 1991. -254 p.(Ru)

2. Kantelhardt, Jan W., et al. "Multifractal detrended fluctuation analysis of nonstationary time series." Physica A: Statistical Mechanics and its Applications 316.1-4 (2002): 87-114.

3. Lyubushin, A.A. and Sobolev, G.A., Multifractal Measures of Synchronization of Microseismic Oscillations in a Minute Range of Periods, Fiz. Zemli, 2006, no. 9, pp. 18-28 [Izv. Phys. Earth (Engl. Transl.), 2006, vol. 42, no. 9, pp. 734-744].

4. Lyubushin, A.A. Data analysis of geophysical and environmental monitoring systems (Geophysical and Ecological Monitoring Data Analysis), Moscow: Nauka, 2007. (Ru)

5. Lyubushin, A.A., Microseismic Noise in the Low-Frequency Range (Periods of 1-300 min): Properties and Possible Prognostic Features, Fiz. Zemli, 2008, no. 4, pp. 17-34 [Izv. Phys. Earth (Engl. Transl.), 2008, vol. 44, no. 4, pp. 275-290].

6. Oynakov E., I. Aleksandrova Seismic characteristics of the earthquake of 10/28/2019 that occurred in the seismogenic region of Vrancea, Romania. BULGARIAN ACADEMY OF SCIENCES, Problems of Geography, 2019, Sofia, no 1, pp. 18-28.

7. Oynakov E., Fractal characteristics of random fluctuations of seismic records, Problems of Geography, 2019, in print

8. Sobolev, G.A., Lyubushin, A.A., and Zakrzhevskaya, N.A., Asymmetrical Pulses, the Periodicity and Synchronization of Low-Frequency Microseisms, Vulkanol. Seismol., 2008, no. 2, pp. 135-152 [J. Volcanol. Seismol. (Engl. Transl.), 2008, vol. 2, no. 2, pp. 118-134]. 